\title{
A importância de vídeos educacionais do YouTube na formação inicial de professores
}

Carla Denize Ott Felcher carlafelcher@gmail.com 0000-0002-9733-9451

Universidade Federal De Pelotas, Pelotas, Rio Grande do Sul, Brasil.

Crisna Daniela Krause Bierhalz crisnakrause@gmail.com 0000-0002-5117-6415 Universidade Federal do Pampa, Dom Pedrito, Rio Grande do Sul, Brasil.

Vanderlei Folmer vandfolmer@gmail.com 0000-0001-6940-9080

\section{RESUMO}

Este artigo objetiva compreender a influência da utilização de vídeos educacionais do YouTube no processo de formação inicial de professores. A metodologia empregada foi qualitativa, através de questionário misto respondido por 153 acadêmicos de Universidades Públicas do Rio Grande do Sul. Sendo 75 licenciandos do Curso de Ciências da Natureza, 33 do Curso de Educação Física e 45 do Curso de Matemática. Os dados produzidos foram apresentados em gráficos, tabelas e nuvens de palavras e apontam que a grande maioria dos acadêmicos assistem vídeos educacionais do YouTube, sendo o curso de Matemática o que lidera a pesquisa e, também, esse curso assiste a maior quantidade de vídeos no semestre. Os acadêmicos buscam os vídeos principalmente para esclarecer dúvidas e mais de $91 \%$ consideram esta plataforma importante na formação. Conclui-se que os vídeos fazem parte da experiência formativa das três Licenciaturas investigadas, fato que merece atenção e discussão.
\end{abstract}

PALAVRAS-CHAVE: Vídeos educacionais do YouTube. Formação inicial de professores. Tecnologias Digitais. 


\section{INTRODUÇÃO}

Muitas publicações discutem aspectos relacionados à formação de professores, alguns focados na formação inicial, outros na formação continuada (IMBERNÓN, 2011). Em que pese à relevância da temática, inúmeras indagações persistem abertas, entre elas a inserção e a utilização das tecnologias nos cursos de Licenciatura e a dicotomia que circunda a relação entre gerações imigrantes (professores em exercício) e nativos digitais (professores em formação).

Neste trabalho compreendemos a formação docente na perspectiva sócio histórica, definida por Freire (1996) como aquela impossível de ser realizada alheia aos aspectos do mundo do trabalho, da história de vida, da prática social. "Formação que perpassa pelo exercício da criticidade, que implica a promoção da curiosidade, do reconhecimento das emoções, da sensibilidade e da afetividade" (FREIRE, 1996, p. 45).

As palavras de Freire ecoam em um momento no qual vários documentos legais sinalizam para uma formação mais humana e menos técnica, ultrapassando a ideia instaurada nos anos 70 , dentro de uma perspectiva tecnicista e epistemologicamente positivista, no qual o professor cumpre o papel de técnico e transmissor de conhecimentos (MONTEIRO, 2001).

As Diretrizes Curriculares Nacionais para a formação inicial em nível superior e para formação continuada aprovada em julho de 2015 , reacende a discussão sobre a formação docente numa perspectiva formativa, ao mencionar que a ação do profissional do magistério da educação básica é permeada por dimensões técnicas, políticas, éticas e estéticas. Ainda ressalta que a sólida formação envolve o domínio e o manejo de conteúdos e metodologias, diversas linguagens e inovações, contribuindo para ampliar a visão e a atuação desse profissional. Neste sentido compreende-se que a formação de professores deve estar alinhada às novas demandas vividas pela sociedade (BRASIL, 2015, p. 03).

Diante do exposto, consideramos imperativo discutir sobre a utilização das tecnologias, em especial a utilização dos vídeos pelos licenciandos, considerando que o êxito no prosseguimento dos componentes curriculares e porque não dizer na conclusão da graduação está atrelada, em muitas vezes, a busca e a utilização destes.

Segundo Domingues (2014) os jovens utilizam vídeos da internet também como fonte de pesquisa para fins de estudo, corroborando situações vividas pelos pesquisadores em sala de aula quando se torna comum os alunos mencionarem a busca por vídeos no YouTube no sentido de compreender conceitos conceituais ou muitas vezes para conseguir realizar os exercícios. Alguns ressaltam que preferem assistir aos vídeos, pois podem pausar, retroceder e adiantar a explicação no momento oportuno, além de buscarem explicações com uma linguagem que dizem ser mais fácil que a do professor (BORBA; OECHSLER, 2017).

Partindo da premissa que a utilização de vídeos é uma realidade nos cursos de graduação, objetivamos neste artigo compreender as influências de vídeos educacionais do YouTube no processo de formação inicial de professores, por meio de uma pesquisa qualitativa, na qual aplicou-se um questionário a 153 acadêmicos dos Cursos de Licenciatura em Ciências da Natureza, Educação Física e Matemática, situados em três Universidades públicas do Rio Grande do Sul. 


\section{A FORMAÇÃO DE PROFESSORES PERMEADA POR TECNOLOGIAS DIGITAIS}

As Tecnologias Digitais (TD) são realidade indiscutível no dia a dia, presente entre os mais diversos públicos e capaz de transformar hábitos, atitudes e inclusive o modo de ser das pessoas. Sendo, portanto, plausível de atenção no meio educacional. Para Kenski (2012, p. 43) "Assim como na guerra, a tecnologia é essencial para a educação. Ou melhor, educação e tecnologias são indissociáveis".

Quando a defesa é pelas TD na educação, aborda-se entre as possibilidades, a utilização na formação de professores. Assim, um dos desafios impostos a formação desses profissionais é a necessidade de discussão que perpassa pela utilização das tecnologias, principalmente quando se trata do ensino presencial.

Acredita-se que o acesso à tecnologia e programas de formação de professores pode contribuir significativamente para que o docente se sinta mais preparado e capacitado para o uso didático das tecnologias. Desta forma, alunos que vivenciam durante seus processos de formação acadêmica momentos em que podem fazer uso pedagógico das tecnologias, possuem maiores chances de compreender e utilizar futuramente tais tecnologias, sentindo-se mais seguros em relação ao seu uso (GARCIA, 2011, p. 81).

Nessa perspectiva Felcher et al (2017) relatam a importância de uma prática pedagógica com a produção de vídeos pelos acadêmicos. A proposta foi desenvolvida com 256 acadêmicos do Curso de Licenciatura em Matemática a distância, em 6 polos e consistiu no estudo, planejamento, produção e edição de um vídeo que abordasse conceitos matemáticos a partir dos anos finais do Ensino Fundamental. Para os autores tal prática possibilita explorar e potencializar o ensino de um conteúdo de forma de diferente, favorecendo que eles empreguem as tecnologias digitais nas suas práticas educativas juntamente com um novo olhar para o ensino da Matemática.

Para Moran, Masseto e Behrens (2008, p. 103), "a inovação não está restrita ao uso da tecnologia, mas também a maneira como o professor vai se apropriar desses recursos para criar projetos metodológicos que superem a reprodução do conhecimento e levem a produção do conhecimento". Deste modo, é fundamental que a tecnologia esteja relacionada às competências e aos objetivos de ensino e aprendizagem. A Base Nacional Comum Curricular (BNCC) na sua $5^{5}$ competência geral da Educação Básica traz que:

Compreender, utilizar e criar tecnologias digitais de informação e comunicação de forma crítica, significativa, reflexiva e ética nas diversas práticas sociais (incluindo as escolares) para se comunicar, acessar e disseminar informações, produzir conhecimentos, resolver problemas e exercer protagonismo e autoria na vida pessoal e coletiva (BRASIL, 2018).

A competência citada prevê o uso das TD numa perspectiva abrangente e que coloca o aluno na condição de protagonista, de autor do próprio conhecimento. Uma perspectiva que supera o uso "domesticado" da tecnologia. Expressão empregada por Borba, Silva e Gadanidis (2015), que significa utilizá-la para manter intactas práticas que eram desenvolvidas com outro tipo de mídia. Ou ainda, fazer com a tecnologia o que já vinha sendo feito com o auxílio de outra.

Assim, para que as TD sejam amplamente utilizadas e com o devido potencial, volta-se a reafirmar a importância da formação do professor. Assim, a formação deve ser de qualidade possibilitando o conhecimento do computador, das redes e 
suportes midiáticos em variadas e distintas atividades de aprendizagem, de modo a identificar a melhor maneira de utilizar a tecnologia para abordar um determinado tema ou um projeto (KENSKI, 2012).

Para Pinto e Silva (2017) as matrizes curriculares apontam que $68,6 \%$ dos cursos de licenciatura não possuem disciplinas com foco na tecnologia, sendo, portanto, segundo o autor, necessária a inserção de disciplinas obrigatórias na formação inicial que possam introduzir experiências com tecnologias digitais. No entanto, o entendimento nesta investigação é de que o foco na utilização das TD na formação do professor deve estar para além de disciplinas específicas, o conjunto de disciplinas deve estar atento a essa realidade e atualmente o que está expresso na BNCC.

\section{TECNOLOGIAS DIGITAIS \& VÍDEOS DIGITAIS}

Considerando a importância das TD na educação e as pesquisas que vêm sendo desenvolvidas, Borba, Silva e Gadanidis (2015) denominam como quarta fase das TD no ensino da Matemática, a fase vivenciada atualmente, e que se consolidou a partir de 2004. Essa fase é caracterizada pela quantidade e qualidade de conexão da internet, que permite estar conectado o tempo todo e em todo lugar.

Esta quarta fase é caracterizada por diversos aspectos, entre eles, destacamse o uso de vídeos da Internet; produção e edição de vídeos; objetos virtuais de aprendizagem; ambientes virtuais de aprendizagem; câmeras digitais, jogos e aplicativos; estar online em tempo integral; celulares inteligentes; internet na sala de aula; redes sociais (Facebook); múltiplas identidades onlines, entre outros (BORBA; SILVA; GADANIDIS, 2015).

O surgimento de uma nova fase não exclui a anterior. As fases vão se integrando e se modificando de acordo com as características do momento. Os vídeos são marcantes nesta quarta fase, sejam produzidos ou compartilhados, graças as facilidades advindas das tecnologias. Para Moore (2010) em virtude do dinamismo das tecnologias a produção de vídeos digitais de curta duração está cada vez mais popular. E entre as páginas com maior número de acessos na internet, estão aquelas que permitem assistir aos vídeos e disponibilizá-los.

O vídeo articula imagens, sons, sintetiza textos, parte do concreto, do imediato e é predominantemente audiovisual, criando uma superposição de códigos e significações (MORAN; MASSETO; BEHRENS, 2012). Ainda segundo Kenski (2008) a imagem, o som e o movimento proporcionados pelos vídeos, oferecem informações mais realistas em relação ao que está sendo ensinado. Deste modo, se bem utilizadas, provocam a alteração dos comportamentos de professores e alunos, levando-os ao melhor conhecimento e melhor aprofundamento do conteúdo estudado.

Para Ferrés (1996), com a utilização de um vídeo podemos iniciar um novo conteúdo, instigar a curiosidade pelo tema trabalhado e até mesmo impulsionar para novos diálogos que se correlacionam com a disciplina. Mais recentemente, a grande disponibilidade de vídeos na internet encontrados em sites, blogs e redes sociais, vem auxiliando professores na dinâmica de suas aulas e, ao mesmo tempo, vem amparando estudantes em seus estudos dentro e fora do espaço escolar (MICHEL; SANTOS; GRECA, 2004). 
No entanto, conforme Moran (1995) o vídeo ajuda o professor, atrai os alunos, mas não modifica substancialmente a relação pedagógica. Neste sentido, Bergmann e Sams (2018) defensores da Sala de Aula Invertida destacam os vídeos, alertando para a necessidade de uma análise cuidadosa, no sentido de identificar se esta é ou não é ferramenta mais adequada aos objetivos que se tem. Inclusive, apontam que a tecnologia não deve ser utilizada somente por "amor".

Valente (2015), ao explanar sobre o ensino híbrido, destaca que os vídeos gravados têm sido um dos recursos mais utilizados pelo fato do aluno poder assistilos quantas vezes necessárias e dedicar maior atenção aos conteúdos em que apresenta maior dificuldade. Além disso, alguns materiais são navegáveis, ou seja, possuem recursos tecnológicos de interação, tais como: animação, simulação, laboratório virtual, entre outros, ele pode aprofundar mais seus conhecimentos.

Em linhas gerais, a abordagem sobre vídeos centra-se em vídeos produzidos pelos estudantes ou utilizados pelos professores, podendo ser produzido pelo próprio professor ou por terceiros. Gomes (2018) apresenta uma proposta de um plano de aula para a utilização de vídeos pelos professores, busca apoiar o professor para que este selecione e avalie o vídeo que fará parte do seu planejamento de aula e assim faça uma escolha qualitativa do recurso audiovisual.

O objetivo da pesquisa de Gomes (2018) é de extrema relevância, já que a utilização de qualquer tecnologia, e aqui os vídeos especificamente precisam estar atrelados a objetivos e a um sério planejamento de ensino e aprendizagem. "Ao exibir um vídeo sem muita ligação com a matéria, o aluno percebe que o vídeo é usado como forma de camuflar a aula" (GOMES, 2018, p. 02). Nesta perspectiva, o vídeo, segundo Ferrés (1996) não deve ser utilizado para preencher o tempo vago do aluno, uma prática denominada tapa buraco.

Entre tantas possibilidades e precauções para o uso dos vídeos no meio educacional, segundo Ferrés (1996) só será autenticamente libertadora se for colocada na mão do aluno para que este possa pesquisar, avaliar-se, conhecer, descobrir novas formas de expressão e participar de experiências coletivas. Segundo pesquisa realizada pela Empresa Pearson (2018) à medida que a Geração $Z$ se instala na faculdade, a tecnologia já moldou suas expectativas educacionais e, portanto, espera por experiências mais envolventes e menos demoradas. A tecnologia não é mais um fenômeno transformador para esta geração, mas sim uma parte normal e integral da vida.

\section{METODOLOGIA}

Neste artigo é empregada uma combinação das metodologias qualitativa que busca compreender as relações estabelecidas a partir do objetivo do artigo, enquanto o quantitativo estabelece relações matemáticas no contexto da investigação.

Para tal foi aplicado um questionário misto, com três (3) perguntas fechadas e quatro (4) abertas à 153 acadêmicos de Universidades Públicas do Rio Grande do Sul. Sendo que destes, 75 são estudantes do Curso de Ciências da Natureza, 33 do curso de Educação Física e 45 são do curso de Licenciatura em Matemática. Os participantes desta pesquisa foram escolhidos aleatoriamente, independente do semestre do curso e das disciplinas que estão cursando. 
A tabela 1 constam algumas características dos cursos, que facilitam ao leitor compreender melhor o universo da pesquisa.

Tabela 1 - Panorama geral das Licenciaturas investigadas na pesquisa

\begin{tabular}{cccccc} 
Licenciatura & $\begin{array}{c}\text { Carga } \\
\text { horária } \\
\text { do curso }\end{array}$ & $\begin{array}{c}\text { No de } \\
\text { anos/semestres }\end{array}$ & $\begin{array}{c}\text { No de } \\
\text { alunos } \\
\text { no curso }\end{array}$ & Diurno & Noturno \\
$\begin{array}{c}\text { Ciências da } \\
\text { Natureza }\end{array}$ & 3260 & $5 / 10$ & 164 & X & \\
Educação Física & 3035 & $4 / 8$ & 140 & & X \\
Matemática & 3538 & $5 / 10$ & 220 & X & X \\
\hline
\end{tabular}

Fonte: Autores (2019).

Para apresentar os dados obtidas pelo questionário foram utilizados gráficos, tabelas e a ferramenta WordArt, um software livre, que gera nuvens de palavras. As nuvens de palavra segundo destacam Borba, Almeida e Gracias (2018) é uma técnica nova, na qual é difícil diferenciar o qualitativo do quantitativo. Sendo que essa apresenta com maior destaque as palavras que aparecem com maior frequência no texto. Assim, segundo os autores, "podemos partir de uma ferramenta quantitativa e lançar um olhar qualitativo" (BORBA; ALMEIDA; GRACIAS, 2018, p. 79).

\section{RESULTADOS E DISCUSSÕES}

O YouTube foi fundado em fevereiro de 2005 e adquirido pelo Google em 2006, sendo classificado pela Google como uma plataforma de distribuição de conteúdos (YOUTUBE, 2012). Essa plataforma, segundo Schneider, Caetano e Ribeiro (2012) oportuniza aos usuários, descobrir e compartilhar vídeos, caseiros ou profissionais, criados com originalidade ou modificados numa abordagem alternativa.

Segundo Mattar (2009) a plataforma YouTube pode ser utilizada com muito sucesso em educação e ressalta que os vídeos têm sido cada vez mais utilizados como recurso pedagógico, pois, respeita as ideias de múltiplos estilos de aprendizagem e de múltiplas inteligências: muitos alunos aprendem melhor quando submetidos a estímulos visuais e sonoros, em comparação com uma educação tradicional, baseada principalmente em textos.

Considerando todo o exposto que valoriza e acena para múltiplas possibilidades dos vídeos educacionais, somada a experiência do dia a dia, a qual mostra que não rara as vezes nas quais os alunos utilizam vídeos educacionais, principalmente do YouTube, buscou-se nessa investigação compreender as influências dessa tecnologia no processo de formação inicial de professores.

A primeira pergunta do questionário, com o objetivo de conhecer mais sobre os participantes da pesquisa, refere-se ao ano do curso que os participantes estão matriculados. E, conforme mostra a figura 1 , em ordem decrescente de

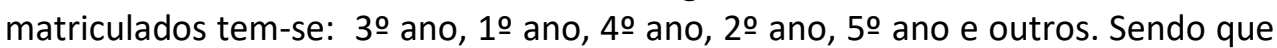


na categoria outros se enquadram os participantes que estão no curso fora do tempo regular.

Figura 1 - Porcentagem de acadêmicos matriculados em cada ano dos cursos

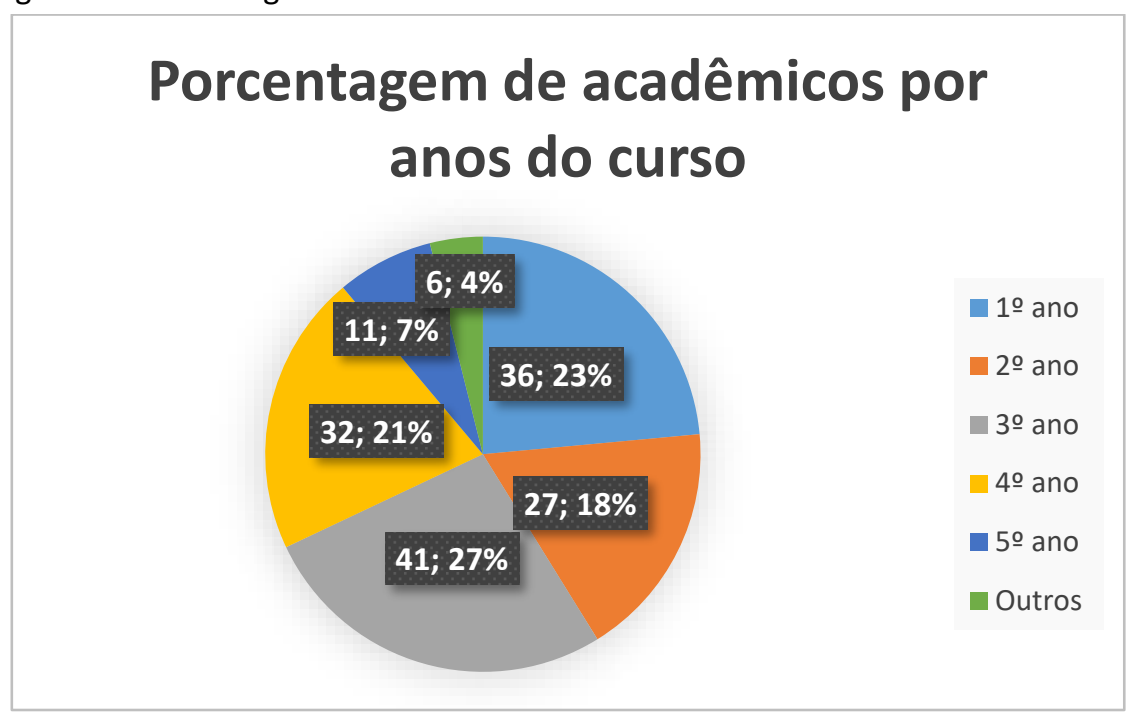

Fonte: Autores (2019).

A segunda pergunta investigou se os licenciandos assistem vídeos do YouTube com o objetivo de aprender conteúdo acadêmicos. A figura 2 mostra que os acadêmicos que mais assistem vídeos são os da Matemática, na sequência está a Ciências da Natureza e posteriormente a Educação Física. Segundo pesquisa realizada por Pearson (2018) uma pesquisa com acadêmicos apontou que YouTube, aplicativos e vídeos são formas preferidas de aprendizado da Geração Z. Enquanto a Geração Millennials prefere livros impressos para o aprendizado.

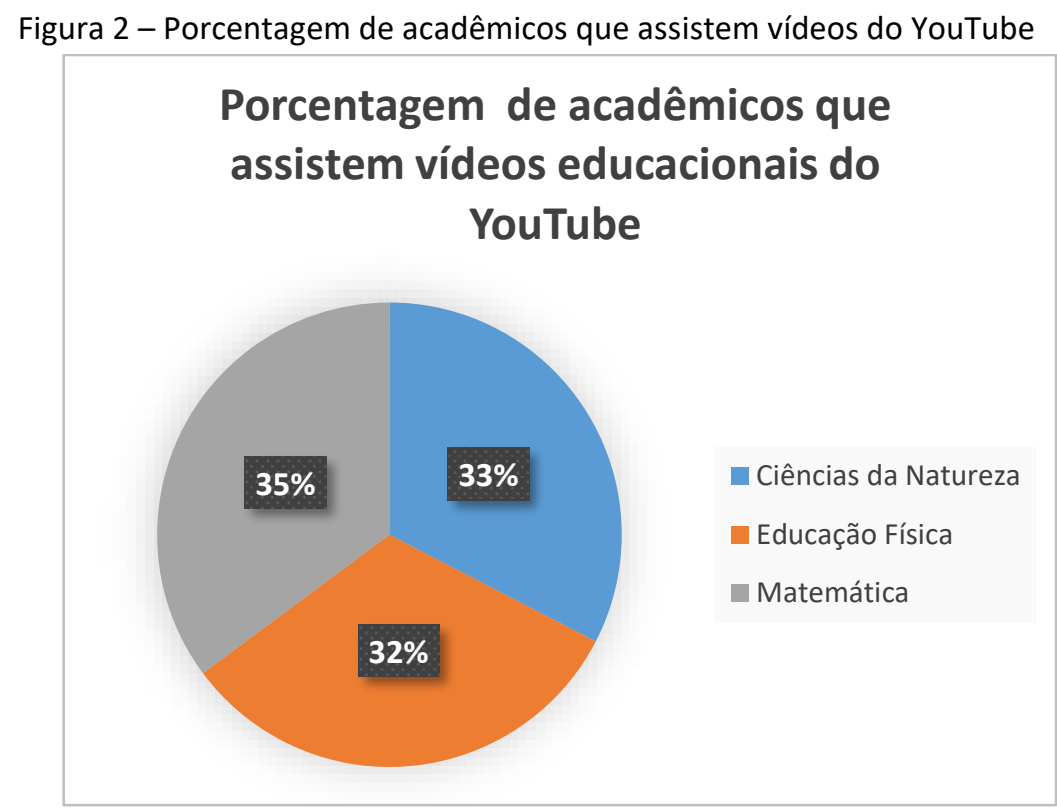

Fonte: Autores (2019).

"A visualização de vídeos ocorre de maneira natural, por ser um hábito dessa geração conectada" (SILVA; PEREIRA; ARROIO, 2017, p. 46). Em uma análise mais 
detalhada, trazendo os números dos acadêmicos que assistem vídeos do YouTube por curso, tem-se os seguintes dados, conforme tabela 2 abaixo:

Tabela 2 - Acadêmicos que assistem vídeos do YouTube

\begin{tabular}{|c|c|c|c|c|c|}
\hline \multicolumn{2}{|c|}{ Ciências da Natureza } & \multicolumn{2}{|c|}{ Educação Física } & \multicolumn{2}{|c|}{ Matemática } \\
\hline Sim & Não & Sim & Não & Sim & Não \\
\hline 67 & 8 & 29 & 4 & 43 & 2 \\
\hline
\end{tabular}

Fonte: Autores (2019).

Percebe-se que é realmente enorme o número de acadêmicos que assiste vídeos educacionais do YouTube nas três licenciaturas. Segundo Borba e Oescher (2018) estes tornaram-se uma espécie de fascínio para muitos, graças a Internet rápida e a facilidade com que se tem acesso a equipamentos que permitem a gravação de áudio e imagens em melhor resolução e com preços cada vez mais acessíveis à população.

Essa facilidade de acesso a equipamentos, produção e compartilhamento de vídeos favoreceu o grande número de YouTubers, que postam vídeos sobre os mais diversos assuntos. A proliferação de vídeos no Youtube cresce exponencialmente, segundo Schneider, Caetano e Ribeiro (2012). Exemplificando, os autores citam que em maio de 2012, uma busca por vídeos com a palavra Matemática no título resultou 71300 vídeos, já a busca com a palavra cálculo no título apresentou 16600 vídeos.

$\mathrm{Na}$ continuidade do questionário, continuariam respondendo aqueles que assistem vídeos educacionais do Youtube (questão 2). A terceira questão perguntava quantos vídeos em média você assiste por semestre, e apresentava 4 opções para assinalar. Os resultados estão apresentados na figura 3.

Figura 3-Quantidade de vídeos que os acadêmicos assistem no semestre

\section{Quantidade de vídeos que os acadêmicos assistem no semestre}

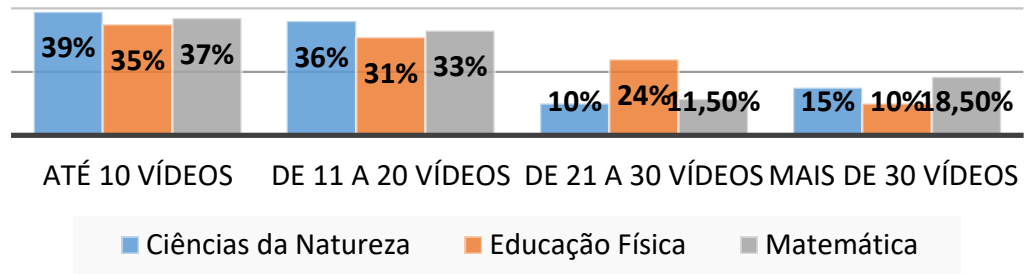

Fonte: Autores (2019). 
A análise da figura 3 possibilita aferir que são os acadêmicos da Matemática os que mais assistem vídeos do YouTube, bem como assistem a maior quantidade de vídeos no semestre.

A grande busca pelos vídeos pode estar relacionada com as características desta tecnologia, apresentadas por Mattar (2009). Segundo o autor, no YouTube, os usuários têm controle sobre o ritmo da apresentação, podendo parar, retroceder e avançar o vídeo. Também, é possível construir ambientes pessoais de aprendizagem com favoritos, listas de reprodução, inscrições, amigos e outros. Pode-se pensar em dois tipos de interação distintos: uma interação básica, já que o usuário pode parar e voltar o vídeo quando quiser, e uma interatividade mais ampla, que pode ser construída por playlists (listas de reprodução) e links que permitem que o usuário pule de um vídeo para outro, além do recurso de comentários disponível no YouTube.

O próximo questionamento, cujas respostas são apresentadas na figura 4, verificou com qual objetivo os acadêmicos assistem os vídeos, e é possível perceber que a maioria assiste com o objetivo de esclarecer dúvidas, seguido por compreender conceitos, aprender, entre outros.

Figura 4 - Nuvem formada a partir do questionamento: com qual objetivo você assiste vídeos educacionais do YouTube?

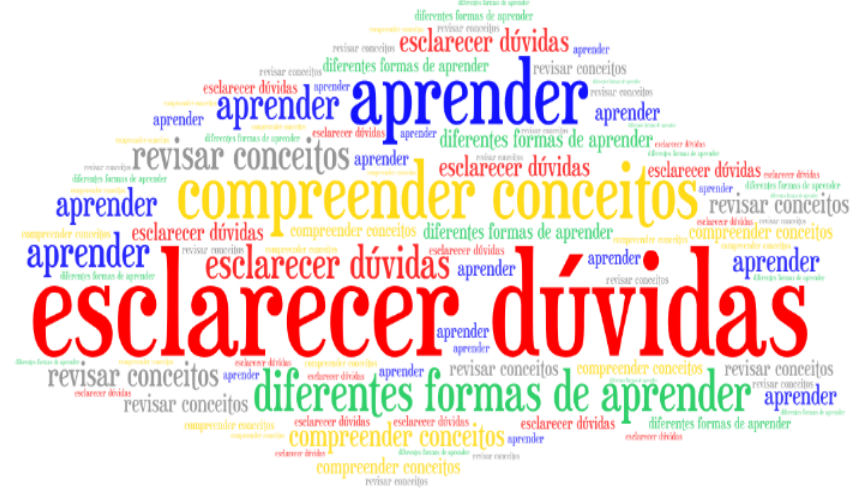

Fonte: Autores (2019).

Grande parte dos acadêmicos citou que assiste os vídeos para esclarecer dúvidas. Segundo Schneider, Caetano e Ribeiro (2012) um dos fenômenos de audiência do YouTube veio justamente de um público de jovens e crianças, que, por iniciativa própria, acessavam os vídeos para esclarecerem suas dúvidas de aprendizado. Complementando, a pesquisa desenvolvida por Medina, Braga e Rego (2015) aponta que maior parte de um grupo de 86 estudantes do ensino Médio acessa o YouTube para informação e diversão, sobretudo visando aprender ou revisar conteúdos, uma preparação para os exames escolares.

No entanto, com toda a disponibilidade de informações é importante salientar o expresso por Ferrés $(1996$, p. 33) "O vídeo não substitui o professor, porém impõe mudanças em sua função pedagógica". A necessidade de mudança na prática pedagógica do professor é no sentido de ser um mediador, um orientador dos processos de ensino e aprendizagem, já que apenas transmitir informações, por exemplo, os vídeos podem fazer com eficácia. 
O quarto motivo pelo qual os acadêmicos procuram os vídeos do YouTube é em busca de diferentes formas de aprender. Motivo bastante relevante se considerarmos que as pessoas aprendem de maneira diferente e o professor por vezes, tem apenas um modo de ensinar. O vídeo tem um poder de ilustração muito forte, prende atenção quando bem estruturado e elaborado. Tem movimento, áudio e, muitas vezes, é autoexplicativo (MATTAR, 2009).

Lançar mãos de vídeos seja para complementar, ilustrar ou esclarecer dúvidas dos alunos tem sido uma prática comum para certos professores, tanto para uso na própria sala de aula, como para uso posterior. Segundo Schneider, Caetano e Ribeiro (2012) há professores que utilizam seus próprios vídeos como um meio para produzir conhecimento, através da construção de vídeos experimentais com alunos e seu posterior compartilhamento.

Os acadêmicos também foram perguntados em quais disciplinas eles procuram assistir vídeos. As respostas foram organizadas e apresentadas por curso, conforme o quadro 1 , abaixo.

Quadro 1 - Disciplinas que os alunos assistem vídeos

\begin{tabular}{|c|c|c|}
\hline Ciências da Natureza & Educação física & Matemática \\
\hline & & Cálculo 26 \\
& & Matemática 15 \\
& & Geometria 10 \\
Química 37 & Anatomia 19 & Física 9 \\
Biologia 26 & Fisiologia 12 & Álgebra 7 \\
Física 23 & Cinesiologia 9 & Aritmética 4 \\
Matemática 18 & Biomecânica 9 & IEM 2 \\
Ciências natureza 10 & Esporte 5 & EDO 2 \\
Didáticas 3 & Todas 2 & Educ Matemática 2 \\
Português 1 & Didática 1 & Lema 1 \\
& Antropologia 1 & Lógica 1 \\
& Bioestatística 1 & Prigonometria 1 \\
& Psicologia 1 & Programação 1 \\
& & Análise real 1 \\
\hline
\end{tabular}

Fonte: Autores (2019).

No curso de Ciências da Natureza a disciplina que mais os acadêmicos assistem vídeos é Química. Em Educação Física é Anatomia e em Matemática é Cálculo. Cabe apensas o questionamento, considerando que este não é o foco da pesquisa, se estas disciplinas são caracterizadas pelos alunos como as mais complexas, difíceis de cada curso? Ou são aquelas nas quais os alunos demonstram maiores dificuldades? Ou o acesso aos vídeos pode estar relacionado a metodologia utilizada pelo professor?

A sexta pergunta: o YouTube é importante para a sua formação inicial? Justifique. Entre os acadêmicos que consideram importante e muito importante o YouTube somam $91 \%$ dos participantes, conforme quadro 2 . 
Quadro 2 - A importância do YouTube na formação dos acadêmicos

\begin{tabular}{|l|l|}
\hline Importante 65\% & $\begin{array}{c}\text { Comentários dos acadêmicos } \\
\text { "É importante, porque me ajuda a } \\
\text { aprender conteúdos que tenho } \\
\text { dificuldade em sala de aula" }\end{array}$ \\
\hline Muito importante 26\% & $\begin{array}{c}\text { "Muito importante. Com certeza em } \\
\text { certas disciplinas devo minha aprovação } \\
\text { aos professores do YouTube" }\end{array}$ \\
\hline Pouco importante 9\% & $\begin{array}{c}\text { "É pouco importante, pois muitas vezes } \\
\text { não consigo alcançar claramente o } \\
\text { conteúdo que procuro" }\end{array}$ \\
\hline
\end{tabular}

Fonte: Autores (2019).

As justificativas dos acadêmicos para a importância do YouTube no processo de aprendizagem e inclusive no prosseguimento da formação coloca em cheque pontos da reflexão pessimista tecida por Juhasz (2008) e apresentada por Mattar (2009). Para a pesquisadora o amadorismo dos vídeos do YouTube torna difícil seu aproveitamento acadêmico e ainda, o ensino superior está ligado ao complexo, não ao simples prazer e a diversão característicos dos vídeos do YouTube.

Há supostamente no mundo acadêmico uma necessidade de reafirmar uma complexidade que não admite diversão e prazer no ensino e aprendizagem. Nas palavras de Mattar (2009) seria uma resistência e uma recusa da academia em mudar. Porém, o usuário do YouTube pode facilmente construir seu ambiente pessoal de aprendizagem (MATTAR, 2009).

A última questão perguntava quais fatores são considerados pelo acadêmico ao escolher os vídeos do YouTube para assistir. As respostas foram categorizadas em três: canal (figura 5), vídeo (figura 6) e autoria do vídeo (figura 7), sendo cada umas das categorias apresentadas em uma nuvem de palavras.

Figura 5 - Nuvem formada com os fatores relacionados ao canal

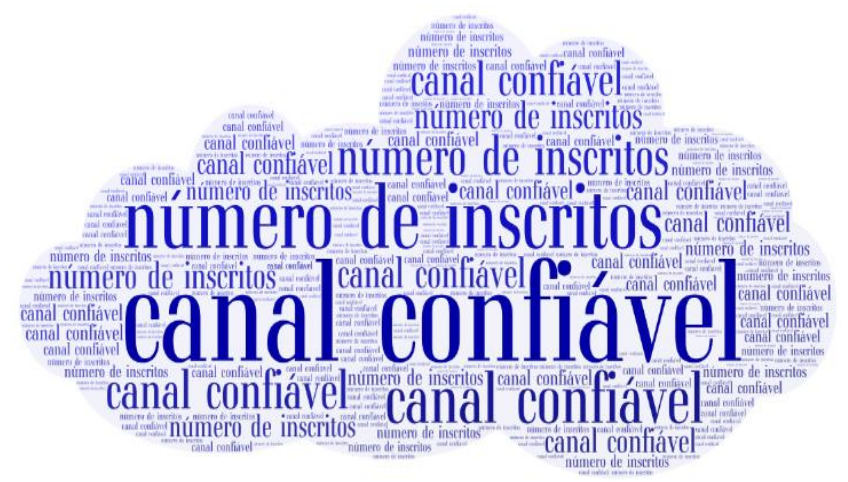

Fonte: Autores (2019). 
Em se tratando de canal, o motivo canal confiável se destaca. Para Borba e Oescher (2018) os Youtubers têm seus seguidores, que possuem afinidade com o tema postado, curtindo, seguindo e compartilhando essas publicações. E assim, os temas explorados são os mais variados, inclusive conteúdos didáticos, possibilitando que cada vez mais os estudantes encontrem no YouTube material que possa sanar dúvidas das matérias escolares (BORBA; OESCHER, 2018).

Figura 6 - Nuvem formada com os fatores relacionados ao vídeo

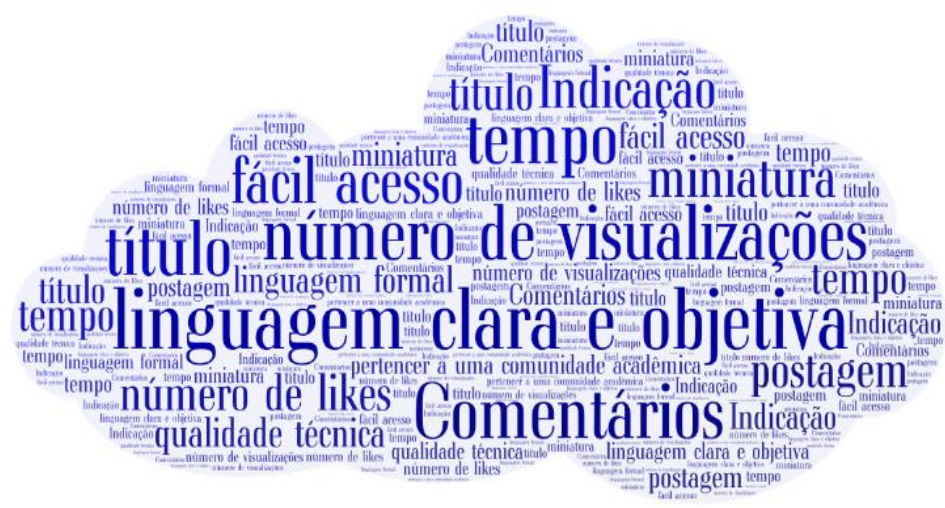

Fonte: Autores (2019).

Na categoria relacionada ao próprio vídeo, os acadêmicos citaram como motivo para a escolha a linguagem clara e objetiva. Segundo Schneider, Caetano e Ribeiro (2012) a de se considerar que o usuário procura no vídeo uma informação clara, objetiva e agradável, por isso os elementos compositivos devem ser pensados no sentido de auxiliar nesse processo. A relação entre som, imagem e texto deve ser interconectada e relacionada através dos títulos, legendas e massa de textos, especialmente quando os textos são priorizados na apresentação.

Entende-se que o motivo citado acima esteja relacionado com um outro apresentado pelos acadêmicos que é o tempo. Afinal, a maioria dos acadêmicos busca no YouTube esclarecer dúvidas, ou seja, explicações e/ou explanações pontuais. Sendo o tempo um motivo fundamental na tomada de decisão e um fator bastante discutido na atualidade. Neste sentido, Bergmann e Sams (2018) citam que se está ensinando equações do segundo grau, ensine apenas equação do 20 grau, é preciso limitar um tópico por vídeo, sendo que, eles têm procurado produzir vídeos de 10 minutos. No entanto, segundo Guo, Kim e Rubim (2014), é importante investir em vídeos de até 6 minutos, pois, vídeos mais curtos são muito mais envolventes.

Interessante mencionar que mesmo com todo o incentivo do ambiente acadêmico a utilização de fontes confiáveis, apenas um aluno menciona escolher o vídeo considerando o pertencimento a comunidade acadêmica, evidenciando um distanciamento entre o que é vivido no ensino superior e as ações do dia a dia. 
Figura 7 - Nuvem formada com os fatores relacionados ao autor do vídeo

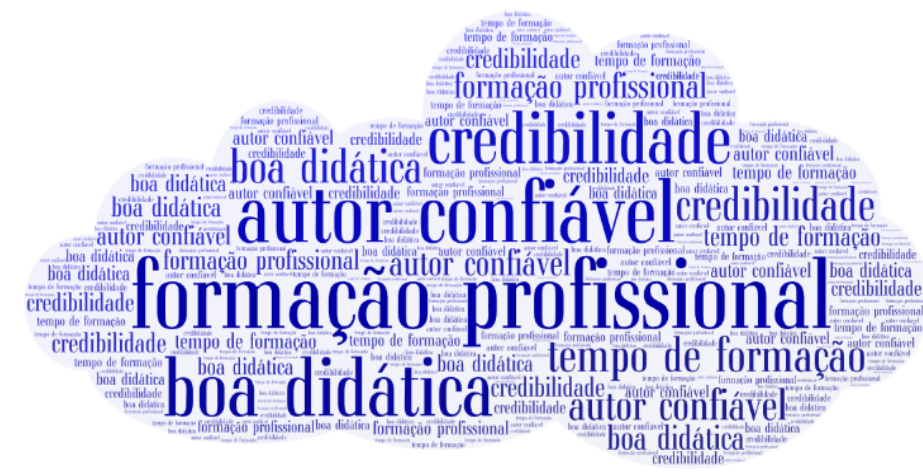

Fonte: Autores (2019).

Na categoria referente ao autor do vídeo, destaca-se a formação do profissional autor do vídeo. Observa-se que muitos vídeos são produzidos por professores e é exatamente estes que os acadêmicos preferem.

A apresentação desses resultados destaca a importância do YouTube na vida dos acadêmicos, o que justifica atenção por parte de alguns educadores que ainda não perceberam o potencial dos vídeos, nem as diversas possibilidades que esta plataforma oferece. É preciso, segundo Moran, Masseto e Behrens (2008) que os professores aprendam a não impor um padrão único de ensinar, afinal o poder da interação não está nas tecnologias, mas nas mentes humanas.

\section{CONSIDERAÇÕES FINAIS}

As tecnologias digitais são realidade irreversível no dia a dia das pessoas. Nesse contexto estão os vídeos digitais que atualmente são produzidos, editados e compartilhados com tamanha facilidade. Graças ao fácil acesso a equipamentos e também o advento da Internet. $O$ qual permite que com um único aparelho, por exemplo, o smartphone, o vídeo seja produzido e seja disponibilizado na rede.

Se produzir, editar e compartilhar vídeos é algo natural do ser humano na atualidade, assisti-los é ainda um processo mais corriqueiro. E assim somos "jogados" para o YouTube, uma plataforma de vídeos que abriga os mais diversos e curiosos títulos. Diante de tamanha diversidade seu uso para fins educacionais começou a ganhar espaço e destaque no cenário.

Assim, muitos questionamentos surgem, no sentido de compreender a influência do YouTube na formação inicial do professor. Essa investigação aponta que a grande maioria dos acadêmicos das três Licenciaturas pesquisadas assistem tais vídeos, liderados pela Licenciatura em Matemática. Seria porque a Licenciatura em Matemática é considerada um curso "difícil'? Ainda, a maioria tem por objetivo nesta busca esclarecer dúvidas, uma prática que segundo eles é de grande importância e inclusive responsável pela aprovação em certas disciplinas, o que faz com que $91 \%$ dos acadêmicos considerem o YouTube importante ou muito importante na formação inicial. 
Como perspectivas futuras, considerando o número expressivo de acadêmicos da Matemática que assistem vídeos do YouTube, tem-se como objetivo investigar se os acadêmicos da Licenciatura em Matemática a distância também assistem tantos vídeos do YouTube, com qual objetivo e como compreendem a relação entre esta atividade e sua formação. Afinal, os vídeos, nas Licenciaturas a distância compõe o material instrucional dos cursos. 


\title{
THE IMPORTANCE OF YOUTUBE EDUCATIONAL VIDEOS IN INITIAL TEACHER TRAINING
}

\begin{abstract}
This article aims to understand the influence of using YouTube educational videos in the initial teacher education process. The methodology used was qualitative through a mixed questionnaire answered by 153 academics of Public Universities of Rio Grande do Sul. Being 75 graduates of the Nature Science Course, 33 of the Physical Education Course and 45 of the Mathematics Course. The data produced were presented in graphs, tables and clouds of words and indicate that the vast majority of academics watch YouTube educational videos, with the Mathematics course leading the research, and also this course watches the largest number of videos in the half. Academics seek videos mainly to clarify doubts and more than $91 \%$ consider this platform important in training. It is concluded that the videos are part of the formative experience of the three undergraduate studies, fact that deserves attention and discussion.
\end{abstract}

KEYWORDS: YouTube educational videos. Initial teacher training. Digital Technologies. 


\section{REFERÊNCIAS}

BERGMANN, J.; SAMS, A. Sala de aula invertida: uma metodologia ativa de aprendizagem. Rio de Janeiro: LTC, 2018.

BORBA, M. C.; SILVA, R. S. S; GADANIDIS, G. Fases das tecnologias digitais em Educação Matemática. Belo Horizonte: Autêntica, 2015.

BORBA, M. C; ALMEIDA, H. R. F. L; GRACIAS, T. A. S. Pesquisa em ensino e sala de aula: Diferentes vozes em uma investigação. Belo Horizonte: Autêntica, 2018.

BORBA, M. C. OESCHER, V. Tecnologias na educação: o uso dos vídeos na sala de aula. Revista Brasileira de Ensino de Ciência e Tecnologia, v. 11, n. 2, 2018.

BRASIL. Conselho Nacional de Educação. Diretrizes Curriculares Nacionais para a formação inicial em nível superior (cursos de licenciatura, cursos de formação pedagógica para graduados e cursos de segunda licenciatura) e para a formação continuada. Resolução CNE/CP n. 02/2015, de 1ํ de julho de 2015. Brasília 2015.

BRASIL. Ministério da Educação. Secretaria da Educação Básica. Base Nacional Comum Curricular. BNCC. Brasília, DF, 2016

DOMINGUES, N. S. O papel do vídeo nas aulas multimodais de Matemática Aplicada: uma análise do ponto de vista dos alunos. 2014. Dissertação (Mestrado em Educação Matemática) - Universidade Estadual Paulista "Júlio de Mesquita Filho", Rio Claro, 2014.

FELCHER, C. D. O. et al. Produzindo vídeos, construindo conhecimento: Uma investigação com acadêmicos da Matemática da Universidade Aberta do Brasil. Redin-Revista Educacional Interdisciplinar, v. 6, n. 1, 2017.

FERRÉS, Joan. Vídeo e educação. Porto Alegre: Artes Médicas, 1996.

FREIRE, P. Pedagogia da Autonomia: saberes necessários à prática educativa. São Paulo: Paz e Terra, 1996.

GOMES, A. C. Planos de aula utilizando vídeo no ensino de Matemática: um estudo de caso. In: Encontro Brasileiro de Estudantes de Pós-Graduação em Educação Matemática, 22., 2018. Belo Horizonte, MG. Anais... Belo Horizonte: Universidade Federal de Minas Gerais, Faculdade de Educação, 2018, p. inicialfinal. Disponível em: https://drive.google.com/file/d/1YkM7 hSuDaW0VuNn1U7hMkqoZ68G94rU/vie w. Acesso em: 03/02/2019. 
GÜNTHER, H. Pesquisa qualitativa versus pesquisa quantitativa: esta é a questão. Psicologia: teoria e pesquisa, v. 22, n. 2, p. 201-210, 2006.

GUO, P. J.; KIM, J.; RUBIN, R. How video production affects student engagement: a empirical study of mooc videos. In: Proceedings of the first acm conference on learning @scale conference. ACM, MIT CSAIL, Cambridge, MA, USA: University of Rochester, Rochester, NY, USA, 2014. p. 41-50.KENSKI, 2008

IMBERNÓN, FRASNCISCO. Formação Docente e profissional: formar-se para a mudança e para a incerteza. São Paulo: Cortez, 2011.

KENSKI, V. Educação e tecnologias: o novo ritmo da informação. Campinas: SP, Papirus, 2012.

MATTAR, J. YouTube na educação: o uso de vídeos em EaD. São Paulo: Universidade Anhembi Morumbi, 2009.

MONTEIRO, A. M. F. C. Professores: entre saberes e práticas. Revista Educação \& Sociedade. ano XXII. n. 74. Abril/2001. Disponível em: http://www.scielo.br/pdf/es/v22n74/a08v2274. Acesso em: 26 jan 2019.

MOORE, Michael; KEARSLEY, Greg. A educação a distância: uma visão integrada. Trad. Roberto Galman. São Paulo: Thomson Learning, 2007.

MORAN, J. M. 0 vídeo em sala de aula. Comunicação e Expressão, v.2, n. jan/abril, 1995.

MORAN, J. M.; MASSETO, M. T.; BEHRENS, M. A. Novas tecnologias e Mediação Pedagógica. São Paulo: Papirus, 2008.

PEARSON. New Research Finds YouTube. Video Drives Generation Z Learning Preference. 2018.

SCHNEIDER, C. K.; CAETANO, L.; RIBEIRO, L. O. M. Análise de vídeos educacionais no youtube: caracteres e legibilidade. Renote, v. 10, n. 1, 2012.

SILVA, M. J; PEREIRA, M. V; ARROIO, A. O papel do youtube no ensino de ciências para estudantes do ensino médio. Revista de Educação, Ciências e Matemática, v. 7, n. 2, 2017. 
VALENTE, J. A. Prefácio. In: BACICH, L.; TANZI NETO, A.; TREVISANI, F. M. (orgs.). Ensino híbrido: personalização e tecnologia na educação. Porto Alegre: Penso, 2015, p. 13-17.

YOUTUBE. Sobre o Youtube. Disponível em:

http://www.youtube.com/t/about youtube. Acesso em: 01 fev de 2019.

Recebido: 09 fev. 2019

Aprovado: 08 abr. 2020

DOI: $10.3895 /$ rbect.v13n2.9557

Como citar: FELCHER, C. D. O.; BIERHALZ, C. D. K.; FOLMER, V. A importância de vídeos educacionais do YouTube na formação inicial de professores. Revista Brasileira de Ensino de Ciência e Tecnologia, Ponta Grossa, v.13, n. 2, p. 43-60, mai./ago. 2020. Disponível em:

$<$ https://periodicos.utfpr.edu.br/rbect/article/view/9557>. Acesso em: XXX

Correspondência: Carla Denize Ott Felcher - carlafelcher@gmail.com

Direito autoral: Este artigo está licenciado sob os termos da Licença Creative Commons-Atribuição 4.0 Internacional. 